\title{
Thinking Styles among the Arab-Minority Teachers in the Arab Education System in Israel
}

\author{
Jamal Abu-Hussain*, Nadia Abu-Hussain \\ Al-Qasemi Academic, Israel \\ *Corresponding author: Jamal_ah@qsm.ac.il
}

\begin{abstract}
This study examined the thinking styles prevalent among Arab teachers, given their status as members of a minority, in the Arab education system in Israel. Examination of thinking styles very important for predicting a person's behavior in different situations, and teachers' thinking styles predict some of their professional behavior when at work in school. The teaching profession demands certain personal characteristics, skills, and a wide professional knowledge base together with appropriate thinking and perceptions and thinking styles are considered to be an important aspect of the teacher's work. A central aspect of a person's personality is their thinking style and another, parallel aspect, is their characteristics. Each of the two have their unique contribution and defining structure. A person's thinking style is influenced by culture and social characteristics and different cultures and societies are characterized by different thinking styles. As members of a national minority in Israel, the thinking styles of Arab teachers have not been previously studied, despite the fact that Arab society is undergoing rapid change in the social, economic, political, cultural, and familial spheres and despite the fact that thinking styles of teachers have an important impact on their day-to-day work in school. It is therefore important to study this subject and to examine the prevalent thinking styles among Arab teachers given their status as a minority in the education system in Israel. The study was conducted among 185 Arab teachers who answered a questionnaire about thinking styles. Their responses were analyzed using the SPSS statistic software. The principle findings showed that the most prevalent thinking styles were Type 2 (executive, local, conservative, and oligarchic) and Type 3 (monarchic, anarchic, internal, and external). The least prevalent was Type 1 (legislative, judicial, global, liberal, and hierarchic).
\end{abstract}

Keywords: thinking styles, Arab teachers, Arab education system in Israel

Cite This Article: Jamal Abu-Hussain, and Nadia Abu-Hussain, "Thinking Styles among the Arab-Minority Teachers in the Arab Education System in Israel." American Journal of Educational Research, vol. 6, no. 1 (2018): 32-37. doi: 10.12691/education-6-1-5.

\section{Introduction}

The main goal of an education system is to create a learning and educational environment, which enables maximal learning and development for students in the cognitive, social, emotional, and movement spheres. The teaching profession demands certain personal abilities and characteristics, a wide professional base, responsibility and appropriate thinking and perceptions. Teachers play an important role in developing the abilities, leanings, and thinking styles of their students and their own thinking styles affect their students. Sternberg [1] notes that thinking styles are a group of strategies and methods used by people and professionals for problem solving and for task performing and therefore they are considered to be an important aspect of teachers' behavior at work.

\section{Theoretical Background}

Zhang and Sternberg [2] state that a thinking style is a person's preference for using his cognitive abilities in a certain manner. Sternberg [1] defines thinking styles are a group of strategies and methods used by people for problem solving and for performing tasks and dictating the way in which they perceive, absorb, process, and conceptualize the information. People tend to use a certain thinking style for a specific situation; and while they may have a dominant style, this can be changed to suit changing circumstances. Students' thinking styles are influenced by those of their teachers. Thinking styles are the product of a socialization process; they change over a period of time and are measurable. There is no such thing as a preferred style, nor are there good or bad ones, there are only different ones.

Zhang and Sternberg [3] note that culture influences a person's abilities, leanings and preferences. Culture reinforces creative thinking and thinking styles such as the legislative and the liberal styles. Smith [4] adds that different cultures prefer different thinking styles. For example, in the culture in the USA, innovativeness and the liberal thinking style is preferred; in Japan's conservative culture, a conservative thinking style is preferred; and Arab culture prefers the executive, local, hierarchic and conservative thinking styles $[5,6]$.

Sternberg's [38] Theory of Mental Self-Government states that there are five categories that reflect a person's inner world, and each category includes a group of 
thinking styles. The main claim of this theory is that different forms of self-government reflect the ways in which we govern ourselves and are the external expression of our inner world. The theory tries to explain how we manage our daily cognitive activities. The thirteen thinking styles are divided into five categories:

Functional: legislative, judicial, executive; Forms: monarchic, hierarchic, oligarchic, anarchic; Levels: global, local; Scope: internal, external; Leanings: liberal, conservative [7].

Based on these five categories, it is possible to define and evaluate people. People may change their thinking style both in terms of extremes and flexibility. For example, some people will be liberal in almost every situation, but others will sometimes be liberal and sometimes conservative.

Zhang, [8,9] proposed a different categorization for thinking styles following analysis of the findings of various studies in different cultures. She proposed three groups of thinking styles:

Type 1 thinking styles: creative thinking and complex cognitive thinking. The group includes the following thinking styles: legislative, judicial, global, liberal and hierarchic.

Type 2 thinking styles: Activities with clear standards and less complex cognitive thinking. The group includes the following thinking styles: executive, local, conservative and oligarchic.

Type 3 thinking styles: Includes all the other thinking styles: monarchic, anarchic, internal and external and were not included in the Type 1 and 2 styles. People with Type 3 thinking styles have characteristics from both Types 1 and 2 and use them according to the demands of their work and the circumstances.

A number of researchers note that thinking styles form a central part of a person's personality $[10,11]$ and other scholars claim that personality characteristics and thinking styles are parallel to each other to a certain extent but each one of them has a unique contribution and clear structure that defines them [12,13,37]. Zhang [14,15,37] conducted a number of studies and found that personality characteristics explain a high percentage of the differences between thinking styles. Additional studies found that personality characteristics explain an even higher percentage of the differences between thinking styles [16]. Chamorro-Premuzic and Furnham [17] found that it is easier to change thinking styles than personality characteristics.

Thinking styles play an important role in predicting a person's behavior in various situations, assisting understanding his or her professional behaviors.

Zhang [9] observed in her study that thinking styles contribute to critical thinking behavior. They not only affect class teaching but also the evaluation of academic and non-academic programs. Using the keyword combinations (such as critical thinking, critical thinking disposition, learning styles, cognitive styles and thinking styles).

Buluş [18] found that only two of the thirteen thinking styles (anarchic and conservative) correlated negatively with academic achievement. Moreover, the findings indicated significant relationships between certain thinking styles and the student-teachers' characteristics that were examined.

Zhang [15] found that Type 1 thinking styles consistently encouraged efficient learning, while Type 2 thinking styles impeded it.

Zhang \& Sternberg's [19] research results indicated that six characteristics of teachers correlated significantly with the thinking styles of the theory of mental self-government. These teacher characteristics are: gender, professional work experience outside school settings, the degree of enjoyment in adopting new teaching materials, a tendency for using group projects in assessing student achievement, perceived autonomy for determining the content of what they teach, and their rating of the quality of their students.

$\mathrm{Yu} \& \mathrm{Zhu}$ [20] found that teachers with Type 1 thinking style preferred to use student-based interpersonal behaviors (leadership, friendship, understanding and freedom) methods in the classroom, whereas teachers with Type 2 and 3 thinking styles preferred to use non-studentfocused interpersonal behaviors (profitable and lack of satisfaction).

In a study conducted in Turkey, Emir [21] found a positive correlation between teachers' critical thinking and the following thinking styles: judicial, anarchic, holistic and conservative.

While a number of studies about the most prevalent thinking styles among teachers have been conducted in the Arab world, none have been conducted among teachers belonging to the Arab-minority in Israel. Hader and Sharif [22] studied common thinking styles of 153 student teachers at the University of Mosul in Iraq and found that external, anarchic thinking styles were the most common while the global thinking style the least. Albaqii [23] conducted a similar study among 109 student teachers in schools of education in Jordanian universities. The findings demonstrated that the most prevalent thinking styles were: executive, hierarchic, monarchic and external. Abu Hashem's [24] study was conducted among student teachers in Egypt and Saudi Arabia and found that the anarchic and oligarchic thinking styles were the most prevalent and the least prevalent were the judicial, liberal and external thinking styles. It seems that the relative absence of the global, liberal and judicial styles indicates their inappropriateness for the conservative culture in the Arab world and are more characteristic of the Western world. Grosbard [25] notes that the participants belonging to the Arab sector in Israel were characterized by the external thinking style, which does not encourage the development of the Type 1 thinking style (legislative, judicial, liberal, global, and hierarchic) as much and encourages Type 2 and 3 thinking styles more.

A number of studies examined people's thinking styles with relation to background variables. Zhang [14] notes that males showed a higher level of the legislative, judicial and liberal thinking styles than females. Fer [26] notes that female students tend to display executive and conservative thinking styles whereas male students tend to display global and liberal thinking styles. Nofal and Abu Awad [27] found that males tend to display the legislative and liberal thinking styles and females tend to display the executive and judicial styles. Hussein [28] notes that female pre-school education students tend to use the 
judicial, monarchic and oligarchic thinking styles. Bushra and Omer [29] conducted their study among students at the University of Assiutt in Egypt and found that female students prefer the external thinking style whereas male students preferred the hierarchic thinking style. Nassar and Yudak [30] did not find any correlation between gender and thinking styles.

Buluş [18] found that male participants scored higher on judicial, anarchic, global, internal and liberal scales than females. The dominant thinking styles of the male participants were judicial, anarchic, global, internal and liberal. These styles were not prevalent in female participants. These results suggest that, compared with the female student- teachers, male student- teachers are more likely to use more complex, creativity-generating thinking styles. These findings are compatible with studies by Zhang and Sternberg (2000) and Zhang (2001)[31,32].

With regard to group differences, Buluş [18] found differences in thinking styles when studying students from different years (freshmen and senior) which indicated significant differences between group means in internal, external and conservative scales. Thus, as the level of education increased, high internal and low conservative leanings were observed.

The Arab minority in Israel, is undergoing societal, educational and cultural changes as well as in the status of women, due to exposure to different cultures. However, it is still has characteristics of a developing society undergoing a process of modernization, and still showing clear signs of conservatism. The basic concepts of conservatism are: a high value attached to customs and traditions; a belief in the irrational nature of mankind; faith in some supernatural force guiding human affairs; acceptance of human inequality and social hierarchy; recognition of the need for a sense of community among individuals [24].

The Arab minority in Israel places greater emphasis on its collective identity - which is formed by familial, ethnic and nationalist identity-and less on individual identity. These social values are reflected by a commitment to the family and by the tendency to put the needs of others ahead of one's own [33].

The Arab minority in Israel is in transition phase. On the one hand, it wishes to preserve values and standards that were appropriate for a conservative society in the past. On the other hand, it wants to undergo a process of modernization. This puts the individual in a conflict between the values of the conservative society of the past and modern, present-day society. Thus, despite their desire to change and evolve, the teachers are themselves the product of traditional Arab education, retain many of the teaching methods and find it difficult to adopt educational perspectives that are different from those of the teachers who taught them. Most Arab teachers continue to take traditional pedagogical approaches [34].

The majority of teachers in the Arab minority schools in Israel do not encourage creative thinking among their students [24] and do not enable their students to realize their potential. They also do not challenge their students or enable them to learn through trial and error. The teachers themselves do not make any changes are not curious to learn more $[24,35]$. The relationship between teacher and student is an authoritative one and students are expected to be obedient, conformist and show respect to their teachers.

The thinking styles of Arab teachers in Israel, members of a developing society with unique characteristics, has not been studied sufficiently. Arab society in Israel has recently been undergoing rapid processes of change in the social, economic, political, cultural and familial spheres, and teachers' thinking styles and their influence on their work in schools is important. It is, therefore, important to examine what thinking styles are most common among Arab teachers who are a minority in the Arab education system in Israel.

Based on the literature review, this study will examine two hypotheses:

1. The most prevalent thinking styles among Arab minority teachers will be Type 2 (executive, local, conservative and oligarchic) and Type 3 (monarchic, anarchic, internal and external). Type 1 (legislative, judicial, global, liberal and hierarchic) will be the least prevalent.

2. Background variables (gender, seniority in the profession, stage of study) will influence differences in teachers' thinking styles.

\section{Method}

\subsection{Participants}

185 Arab teachers who work in the Arab education system in Israel in pre-school, elementary and high schools. The teachers were chosen in a random sample from lists of the Ministry of Education's Pisgah In-Service training centers.

\subsection{Study Design}

This is a correlative study that examines the most prevalent thinking styles among Arab teachers in the Arab education system in Israel.

\subsection{Study Variables}

Thinking styles, seniority in teaching, gender, stage of study

\subsection{Study Tools}

The study is based on data gathered from a selfreporting questionnaire distributed to Arab teachers in Israel. The first part of the questionnaire asked about their background variables, and the second part about the main thinking styles of the study.

The thinking styles questionnaire is based on Sternberg's [38] Thinking Styles Inventory to determine the participant's thinking style. However, analysis of the findings was based on Zhang's [8,9] classification. The questionnaire consists of 65 statements which characterize five categories of thinking styles. The respondents are asked to rate themselves on a scale from 1 to 7 , with 1 indicating that they do not agree with the statement at all and 7 indicating that they fully agree. The questionnaire 
consisted of statements from Sternberg's [38] questionnaire and includes all thinking styles. Abu Hashem [36] translated it into Arabic and validated the content. The Arabic version showed the following reliability coefficients of internal consistency (Cronbach's alpha) in the various categories:

First category (functional) $\alpha=0.92$; second category (forms) $\alpha=0.89$; third category (levels) $\alpha=0.93$; fourth category (scope) $\alpha=0.96$; fifth category (leanings) $\alpha=0.91$.

In the current questionnaire, the reliability coefficients of internal consistency (Cronbach's alpha) of the different thinking styles showed:

Type $1 \alpha=0.88$; Type $2 \alpha=0.74$; Type $3 \alpha=0.64$. The entire questionnaire showed a reliability of $\alpha=0.79$.

\subsection{Study Procedure}

The questionnaire was distributed by the study author to teachers. They were explained the study aims and were told that the data would remain anonymous and be used for study purposes only. All the teachers agreed to participate; they cooperated and completed the questionnaires during the first meeting. The data was analyzed using the SPSS statistical analysis software as well as theoretical statistics to examine the study hypotheses.

\section{Findings}

First hypothesis: The most prevalent thinking styles among Arab minority teachers will be Type 2 (executive, local, conservative and oligarchic) and Type 3 (monarchic, anarchic, internal and external). Type 1 (legislative, judicial, global, liberal and hierarchic) will be the least prevalent.

Table 1 shows that the most prevalent thinking styles among Arab teachers are Type $2(\mathrm{M}=5.2, \mathrm{SD}=1.05)$ and Type $3(\mathrm{M}=4.82, \mathrm{SD}=.95)$ and the least prevalent is Type $1(\mathrm{M}=4.34, \mathrm{SD}=1.06)$.

The data in Table 2 shows that there are no statistical differences in thinking style groups between the new and senior teachers. The senior teachers have the highest mean in the first thinking styles group, and the new teachers have the highest mean in the third thinking styles group.

The data shows that there are no statistical differences in thinking style groups between male and female teachers.
The male teachers have the highest mean in the second and third thinking styles groups and the female teachers have the highest mean in the first thinking styles group.

The data shows that there are no statistical differences in thinking style groups between teachers at different stages of study. The teachers who teach in pre-school and elementary schools have the highest mean in the first thinking style group, and the high school teachers have the highest average in the second and third thinking styles groups.

Table 1. Prevalent Types and Thinking Styles among Arab Teachers (N=185)

\begin{tabular}{|c|c|c|c|c|}
\hline $\begin{array}{l}\text { Style } \\
\text { Type }\end{array}$ & $\begin{array}{l}\text { Thinking } \\
\text { Style }\end{array}$ & Mean (SD) & $\begin{array}{l}\text { Mean (SD) } \\
\text { per type for } \\
\text { each type }\end{array}$ & $\%$ \\
\hline \multirow{5}{*}{ Type 1} & Legislative & $3.98(1.13)$ & \multirow{5}{*}{$4.34(1.06)$} & \multirow{5}{*}{$\% 62$} \\
\hline & Judicial & $4.56(1.22)$ & & \\
\hline & Hierarchic & $4.78(1)$ & & \\
\hline & Global & $4.17(.82)$ & & \\
\hline & Liberal & $4.22(1.13)$ & & \\
\hline \multirow{5}{*}{ Type 2} & Executive & $5.28(1.06)$ & \multirow{4}{*}{$5.21(1.05)$} & \\
\hline & Oligarchic & $5.05(1.05)$ & & \\
\hline & Conservative & $5.56(.9)$ & & $\% 74.42$ \\
\hline & Local & $4.97(1.2)$ & & \\
\hline & Internal & $4.78(1.01)$ & & \multirow{4}{*}{$\% 68.85$} \\
\hline \multirow[t]{3}{*}{ Type 3} & External & $4.73(.91)$ & $4.82(.95)$ & \\
\hline & Monarchic & $5.07(.97)$ & & \\
\hline & Anarchic & $4.73(.94)$ & & \\
\hline
\end{tabular}

Second hypothesis: Background variables (gender, seniority in the profession, stage of study) will influence differences in teachers' thinking styles.

Table 2. Differences in Thinking Styles among Teachers Based on Seniority

\begin{tabular}{ccccccc}
\hline & New Teachers & \multicolumn{2}{c}{$\begin{array}{c}\text { Senior } \\
\text { Teachers }\end{array}$} & Value & $\begin{array}{c}\text { Statistical } \\
\text { Significance }\end{array}$ \\
\cline { 2 - 5 } & \multicolumn{2}{c}{$\mathrm{N}=71$} & \multicolumn{2}{c}{$\mathrm{N}=114$} & $\mathrm{t}(152)$ & \\
\hline Mean & $\mathrm{SD}$ & Mean & $\mathrm{SD}$ & & \\
\hline Group 1 & 4.82 & 0.43 & 5.25 & 0.55 & 0.27 & 73.0 \\
\hline Group 3 & 5.16 & 0.51 & 81.4 & 0.59 & 0.45 & 66.0 \\
\hline
\end{tabular}

Table 3. Differences in Thinking Styles among Teachers Based on Gender

\begin{tabular}{|c|c|c|c|c|c|c|}
\hline & \multicolumn{2}{|c|}{$\begin{array}{l}\text { Male Teachers } \\
\qquad \mathrm{N}=51\end{array}$} & \multicolumn{2}{|c|}{$\begin{array}{c}\text { Female Teachers } \\
\mathrm{N}=134\end{array}$} & \multirow[t]{2}{*}{$\begin{array}{l}\text { Value } \\
\mathrm{t}(161)\end{array}$} & \multirow[t]{2}{*}{ Statistical Significance } \\
\hline & Mean & $\mathrm{SD}$ & Mean & SD & & \\
\hline Group 1 & 4.95 & 0.64 & 5.21 & 0.55 & 0.22 & 0.83 \\
\hline Group 2 & 5.04 & 0.68 & 5.00 & 0.65 & 0.32 & 0.74 \\
\hline Group 3 & 5.06 & 0.58 & 4.94 & 0.58 & 0.92 & 0.35 \\
\hline
\end{tabular}

Table 4. Differences in Thinking Styles among Teachers Based on Study Stage

\begin{tabular}{|c|c|c|c|c|c|c|c|c|}
\hline & \multicolumn{2}{|c|}{$\begin{array}{c}\text { Pre-School } \\
\quad N=63\end{array}$} & \multicolumn{2}{|c|}{$\begin{array}{l}\text { Elementary School } \\
\qquad \mathrm{N}=67\end{array}$} & \multicolumn{2}{|c|}{$\begin{array}{l}\text { High School } \\
\quad \mathrm{N}=55\end{array}$} & \multirow[t]{2}{*}{$\begin{array}{c}\text { Value } \\
\mathrm{F}(2,154)\end{array}$} & \multirow[t]{2}{*}{ Statistical Significance } \\
\hline & Mean & SD & Mean & SD & Mean & SD & & \\
\hline Group 1 & 5.23 & 0.59 & 5.22 & 0.53 & 4.93 & 0.57 & 0.11 & 0.89 \\
\hline Group 2 & 4.82 & 0.63 & 5.03 & 0.67 & 5.09 & 0.70 & 1.22 & 0.29 \\
\hline Group 3 & 4.81 & 0.62 & 4.97 & 0.59 & 5.17 & 0.61 & 0.67 & 0.51 \\
\hline
\end{tabular}




\section{Discussion}

The aim of this study was to examine which thinking styles are the most prevalent among Arab teachers in Israel. The findings of this study will be discussed and compared with previous studies. The limitations of this study as well as its theoretical and practical implications will be discussed as well.

The first hypothesis was that the most prevalent thinking styles among Arab minority teachers would be Type 2 (executive, local, conservative and oligarchic) and Type 3 (monarchic, anarchic, internal and external). Type 1 (legislative, judicial, global, liberal and hierarchic) would be the least prevalent. This hypothesis was verified. This finding is supported by other studies that examined thinking styles among Arab students in Jordanian, Egyptian and Iraqi universities. The studies found that the most prevalent thinking styles were Types 2 and 3, for example the executive, monarchic, oligarchic and external styles. The least prevalent thinking styles were Type 1 (executive, global, judicial, liberal and hierarchic) [22,23,24].

The verification of the hypothesis shows that Arab minority teachers prefer Type 2 and Type 3 thinking styles. This finding may be attributed to Grosbard's [25] study which found that study participants from Arab society in Israel display an external thinking style that does little to encourage Type 1 thinking style (legislative, judicial, liberal, global and hierarchic) and encourages Types 2 and 3 thinking styles more. In addition, teaching in educational institutions in the Arab education system is mainly frontal, and does not develop creativity and higher order thinking skills. Thus, the Type 1 thinking style is not expressed in schools and Types 2 and 3 are more entrenched among students [24].

This finding may be explained by Smith [4] who notes that different cultures prefer different thinking styles. Some cultures teach their children not to ask questions about certain core values in their religion or about other topics. Others encourage children to ask questions. The social values in the Arab minority in Israel and the teachers who represent these values do not encourage innovativeness and creative thinking and do not encourage the students to ask challenging questions $[33,35]$.

Teachers come to school with their personal thinking styles and teaching methods and these influence the learners' thinking styles. Some schools encourage independent thinking, asking questions and development of problem solving strategies. Other schools only use frontal teaching and dictate to the students how and what to do thus reinforcing the executive thinking style $[4,24]$.

Sternberg [38] claims that in order to create effective learning processes, one must provide the learner with a variety of activities and teaching methods to ensure that at least some of these will be appropriate for his or her thinking style. Different teaching methods are appropriate for different thinking styles. For example, frontal teaching is appropriate for the executive thinking style, and asking questions is appropriate for Type 1 thinking style (legislative and judicial); group work is appropriate is appropriate for the external thinking style; learning through projects and study is appropriate for Type 1 legislative; solving given problems is appropriate for the executive thinking style; working in small groups to find answers for factual questions is appropriate for the external and executive thinking styles; and reading is appropriate for the internal thinking style, etc. This means that if the teacher does not have Type 1 thinking style (legislative, judicial, hierarchic, global and liberal) which is appropriate for certain teaching methods, he or she will find it very difficult to use methods such as asking questions, learning through projects and study and discovery.

In most cases, Arab teachers use frontal teaching methods, which are more appropriate for the executive thinking style, because the student is not required to intervene but to accept the information that the teacher presents him. This method is also more appropriate for learners with the local thinking style [24,38].

Compatibility between teacher and student thinking styles is important; it improves the student's learning and achievements. It is also important to examine the learners' functioning using various evaluation tools that are appropriate for different thinking styles. This insight by researchers is very worrying because the current generation of children has very different thinking styles from their teachers, a consequence of the 21 st century technological revolution. Therefore it would appear that Type 1 thinking style (legislative, judicial, hierarchic, global, and liberal) which is very connected to innovative and varied teaching and evaluation methods is very important and is more appropriate for the students of today [32].

The second hypothesis was that background variables (gender, seniority in the profession, stage of study) will correlate with differences in teachers' thinking styles. This hypothesis was not verified, and no differences were found in teachers' thinking styles based on background variables (seniority, gender and stage of study). This finding is supported by Nassar and Yudak [30] who did not find any correlation between gender and thinking styles. However, the findings show differences that are not statistically significant in preferences for thinking styles based on background variables. Senior teachers with many years of experience in the profession preferred teaching styles from the first group, whereas new teachers preferred thinking styles from the third group. This finding may be explained by the fact that senior teachers are very experienced and are more professionally advanced than new teachers. This finding is supported by Buluş [18].

Male teachers preferred Group 2 (executive, local, conservative and oligarchic) and Group 3 (monarchic, anarchic, internal, and external) thinking styles, whereas female teachers preferred Group 1 thinking styles (legislative, judicial, global, liberal, and hierarchic). This finding may be explained by the fact that the Arab society in Israel is undergoing processes of change in many spheres of life [24]. Female teachers living in a developing society have a greater wish to free themselves from the chains of their male-dominated society. This finding is partly supported by Hussain [28] who found that female pre-school education students tend to use the judicial, monarchic and oligarchic thinking styles.

Female teachers in pre-school and elementary schools preferred Group 2 thinking styles and male teachers in high schools preferred Groups 2 and 3 thinking styles. This finding might be explained by gender, because the 
percentage of females in pre-schools and elementary schools in the Arab education system is $90 \%$, whereas is high school it is only $25 \%$.

\section{Recommendations}

In terms of theory and methodology, we recommend further studies with a larger sample population, which will include male and female, Arab and Jewish teachers as well as a comparative study with other traditional and modern societies. We also recommend examining the influence of teachers' professional development such as meaningful learning on their thinking styles using qualitative and quantitative research tools to this end.

Practically speaking, we recommend that teachertraining colleges take into account the thinking styles of prospective teachers, and that decision makers consider candidates' teaching styles before accepting them for a teaching position in their schools. Appropriate professional development programs should also be implemented for fostering preferred thinking styles among teachers and for raising awareness about this important topic.

\section{References}

[1] Sternberg, R. J. (2002). Thinking styles, Reprinted Edition, UKA, Cambridge University Press.

[2] Sternberg, R. J. \& Zhang, L.F. (2006). Styles of thinking as a basis of differentiated instruction. Theory into Practice, 44(3), 245-253.

[3] Zhang, L. F., \& Sternberg, R. J. (2005). Threefold model of intellectual style. Education Psychology Review, 17(1), 91-110.

[4] Smith, J. (2002). Learning style: Fashion fad or lever for change? The application of learning style theory to inclusive curriculum delivery innovations. Education and Teaching international, 39(1), 63-70.

[5] Alkudat, M., \& El-Mekdadi, H. (2008). Prevalent thinking styles among a sample of students at the King Haled University based on gender, specialization and study stage variables. Journal of the Faculty of Education, Tanta University, (2) 39, 312-336. (Arabic).

[6] Abu-Hashem, M. (2015). Thinking styles in the light of Sternberg's theory: A comparative study among two student samples in Egyptian and Saudi Arabian universities. Saudi Arabia: King Saud University. (Arabic).

[7] Sternberg, R. J. (1995). Self Government. The theory of thinking and learning styles. Education of Thinking, 2, 21-25. [Branco Weiss Institute and the Curriculum Division of the Ministry of Education]. (Hebrew).

[8] Zhang, L. F. (2000). Are thinking styles and personality types related? Educational Psychology, 20(3), 271-284.

[9] Zhang, L. F. (2004). Thinking styles: University students' preferred teaching styles and their conceptions of effective teachers. Journal of Psychology, 138(3), 233-252.

[10] Furnham, A., Jackson, C. J., \& Miller, T. (1999). Personality, learning style and work performance. Personality and Individual Differences, 27(6), 1113-1122.

[11] Jackson, C. J., \& Lawty-Jones, M. (1996). Explaining the overlap between personality and learning style. Personality and Individual Differences, 20(3), 293-300.

[12] Larson, L. M., Rottinghaus, P. J., \& Borgen, F. H. (2002). Metaanalyses of big six interests and big five personality factors. Journal of Vocational Behavior, 61(2), 217-239.

[13] Roodenburg, J., Roodenburg, E., \& Rayner, S. (2012). Personality and intellectual styles. In L. F. Zhang, R. J. Sternberg \& S. Rayner (Eds.), Handbook of intellectual styles: Preferences in cognition, learning, and thinking (209-231). New York, NY: Springer Publishing.

[14] Zhang, L. F. (2002). Thinking Styles and the Big Five Personality Traits. Educational Psychology, 22(1), 17-31.
[15] Zhang, L. F. (2008). Preferences for teaching styles matter in academic achievement: Scientific and practical implications. Educational Psychology, 28, 615-625.

[16] Rosander, P., \& Bäckström, M. (2012). The unique contribution of learning approaches to academic performance, after controlling for IQ and personality: Are there gender differences? Learning and Individual Differences, 22(6), 820-826.

[17] Chamorro-Premuzic, T., \& Furnham, A. (2009). Mainly openness: The relationship between the Big Five personality traits and learning approaches. Learning and Individual Differences, 19(4), 524-529.

[18] Buluş, M. (2006). Assessment of thinking styles inventory, academic achievement and student teacher's characteristics. Education and Science, 31(139), 35-48.

[19] Zhang, L. F., \& Sternberg, R. J. (2010). Thinking styles and teachers' characteristics, 37 (1), 3-12.

[20] Yu, T. M. and Zhu, C. (2011). Relationship between teachers' preferred teacher-student interpersonal behaviour and intellectual styles, Educational Psychology, 31(3), 301-317.

[21] Emir, S. (2013). Contributions of teachers' thinking styles to critical thinking dispositions (Istanbul- Fatih Sample). Educational Sciences: Theory \& Practice, 13(1), 337-347.

[22] Hader, T., \& Sharif, A. (2009). Thinking styles among students at Al Musol University. Journal of the Al Musol University School of Education.10 (2), 155-180. (Arabic).

[23] Albaqii, G. (2012). Styles of thinking and the five major personality traits among student teachers at schools of education in Jordanian universities. Hebron University Research Journal, 7(1), 107-131 (Arabic).

[24] Abu-Hussain, J. (2015). The thinking language of elementary school teachers in the Arab education system in Israel: Implications for teacher education. Open Journal of Business and Management, 3(3), 257-264.

[25] Grosbard, O. (2013). Babel - A guide to the East-West encounter. Beersheba: Ben Gurion University Publishing House. (Hebrew).

[26] Fer, S. (2012). Demographic characteristics and intellectual styles. In L. Zhang, R. Sternberg \& S. Rayner (Eds.). Handbook of intellectual styles (109-130). New York: Springer Publishing.

[27] Nofal, M., \& Abu Awad, P. (2012). Prevalent thinking styles based on the Theory of Self Government among students in Jordanian universities. The Journal of Studies at the Al Najah University, 26 (5), 1217-1257. (Arabic).

[28] Hussein, A. (2011). Thinking styles among pre-school teacher training students. The Journal for Psychological Sciences, Baghdad University, 18, 240-287. (Arabic).

[29] Bushra, Z. \& Omer, M. (2013). The connection between thinking styles and anxiety and violence among university students: A prediction study. The Scientific Journal, 29 (1), 47-53.

[30] Nassar, Y., \& Yudak, Z. (2010). Thinking styles among students of professional studies in Jordan and the correlation with their academic achievements and leanings toward specialization. The Educational Journal, Kuwait, 24 (95), 323-361. (Arabic).

[31] Zhang, L. F., \& Sternberg, R. J. (2000). Are learning approaches and thinking styles related?: A study in two Chinese populations. Journal of Psychology, 134 (5), 469-489.

[32] Zhang, L. F. (2001). Approaches and thinking styles in teaching. The Journal of Psychology, 135(5), 547-561.

[33] Jaraisy, I. (2013). Psychosocial treatment in Arab society. In: M. Hovev, T. Lontal, \& Y. Keten (Eds.), Social Work in Israel: Hakibbutz Hameuchad, Publishing House - Red Line. (Hebrew).

[34] Abu-Hussain, J., \& Essawi, M. (2014). School principals' perceptions of teacher evaluation in the Arab educational system in Israel. Journal of Education and Training Studies, 2(2), 31-43.

[35] Mahamid, A.P. (2012). Is traditional Arab society sufficiently prepared to cope with the success of the postmodern era? Studies in education, society, technology and information, ORT Israel, Issue 13, 35-41. (Hebrew).

[36] Abu-Hashem, M. (2009). The psychometric characteristics of thinking styles according to Sternberg's theory among university students. Saudi Arabia: King Saud University. (Arabic).

[37] Zhang, L. F. (2006). Thinking styles and the big five personality traits revisited. Personality and Individual Differences, 40, 1177-1187.

[38] Sternberg, R. J. (1997). Thinking styles. Boston: Cambridge University Press. 